\title{
MEMORIES OF GROUSE
}

\author{
JERROLD ARMSTRONG, Box 433, Kinistino, Saskatchewan. SOJ $1 \mathrm{HO}$
}

One spring in the 1930s, I was walking in the country 1 or 2 miles west of Melville, after a sleepless night. It was very early in the morning - before sunrise. Suddenly I became aware of something in the distance, a faint gabble of sound. I listened intently, then began walking toward it.

The sun was just beginning to appear above the horizon behind me. The air was cool and still. The country was fairly open with scattered poplar groves - the pasture land of the "west herd" of milk cows. Melville was, I believe, unique in having an "east herd" and a "west herd", each cow belonging to an individual family in the town. [In the morning the cows were driven out to their respective grazing land and in the evening they returned of their own accord, each to its own home stable. ]

As I walked on slowly and silently, the source of the ever-louder cackling, rattling sound came into sight: a large flock of Sharp-tailed Grouse engaged in the courtship behaviour I had read about but had never seen. I continued my cautious approach, step by step, expecting them to spot me and take off at any moment. I was in plain sight; there wasn't a tree or bush within 100 yards. Nearer and nearer I moved in growing amazement that these wild birds were ignoring me. They were in a scattered crowd, so to speak, in an area as I recall about 50 yards wide and 100 yards long. The cocks were displaying and feigning combat; they seemed to be unconcerned, indifferent.

When I was about 40 feet from them, the flock suddenly stopped its noisy activity, froze for a second, then exploded in a crashing flurry of wings and was gone!

I was amazed at the whole thing the strange behaviour of the flock in allowing me to approach so near - until the explanation occurred to me. They

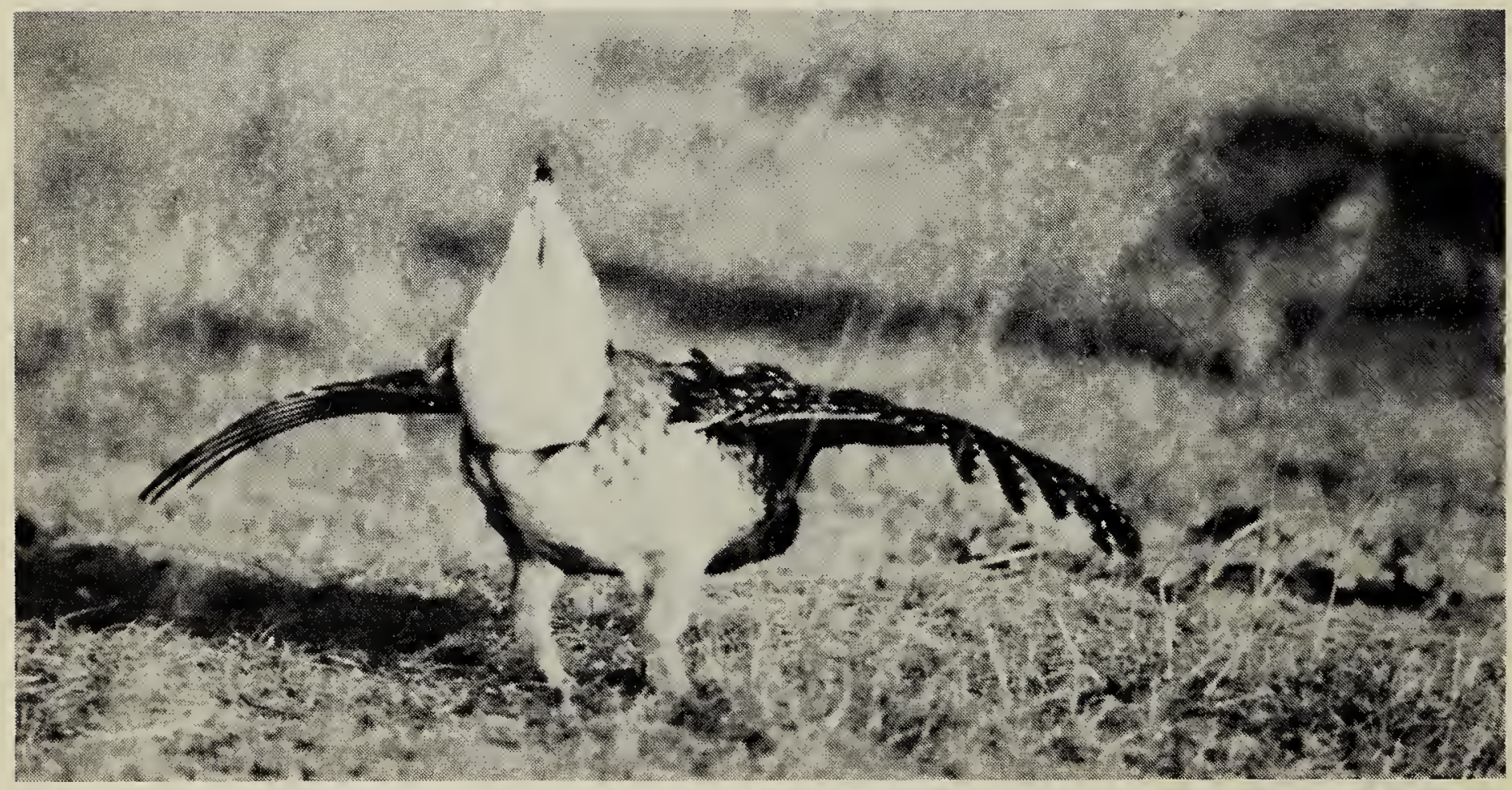


had not heard me because of my cautious silent tread; they had not seen me because the sun rising over the horizon was directly behind me. I was invisible in a blaze of light.

I had somewhat similar experience in southwestern Saskatchewan, in the "Whitemud" or Frenchman River valley only a few miles north of the United States boundary. On this occasion, on horseback, I came even closer to a similar courtship ceremonial of Sage Grouse. Their ritual struck me as being more "orderly." The hens huddled logether in the center of a circle with a radius of 30 to 40 feet. Around the circumference the cocks strutted and displayed with dignity, spreading their pointed tail quills into fans, puffing out their white breasts and inflating and deflating their orange-coloured throat air-sacs with a sound something like the pop of a cork being jerked out of a bottle.
I rode in a sidling slant toward the flock and stopped about 30 feet from their arena. They paid no attention to me. To them, horses were of no significance, and this rider-and-horse was just - a horse.

In my experience no game birds are so adept as the Sage Grouse at hiding - disappearing - in open country with nothing but sparse tufts of cover. They allow you to walk right up and almost tread upon them, then scare the wits out of you as they burst up from the ground at your very feet.

In the Kinistino country in the 1920s, it was a way of the Greater Prairie Chicken, numerous then, early on frosty winter mornings to gather in little groups on top of straw stacks and converse.

I haven't seen a Greater Prairie Chicken or a Sage Grouse for many years. I wonder how they are faring?

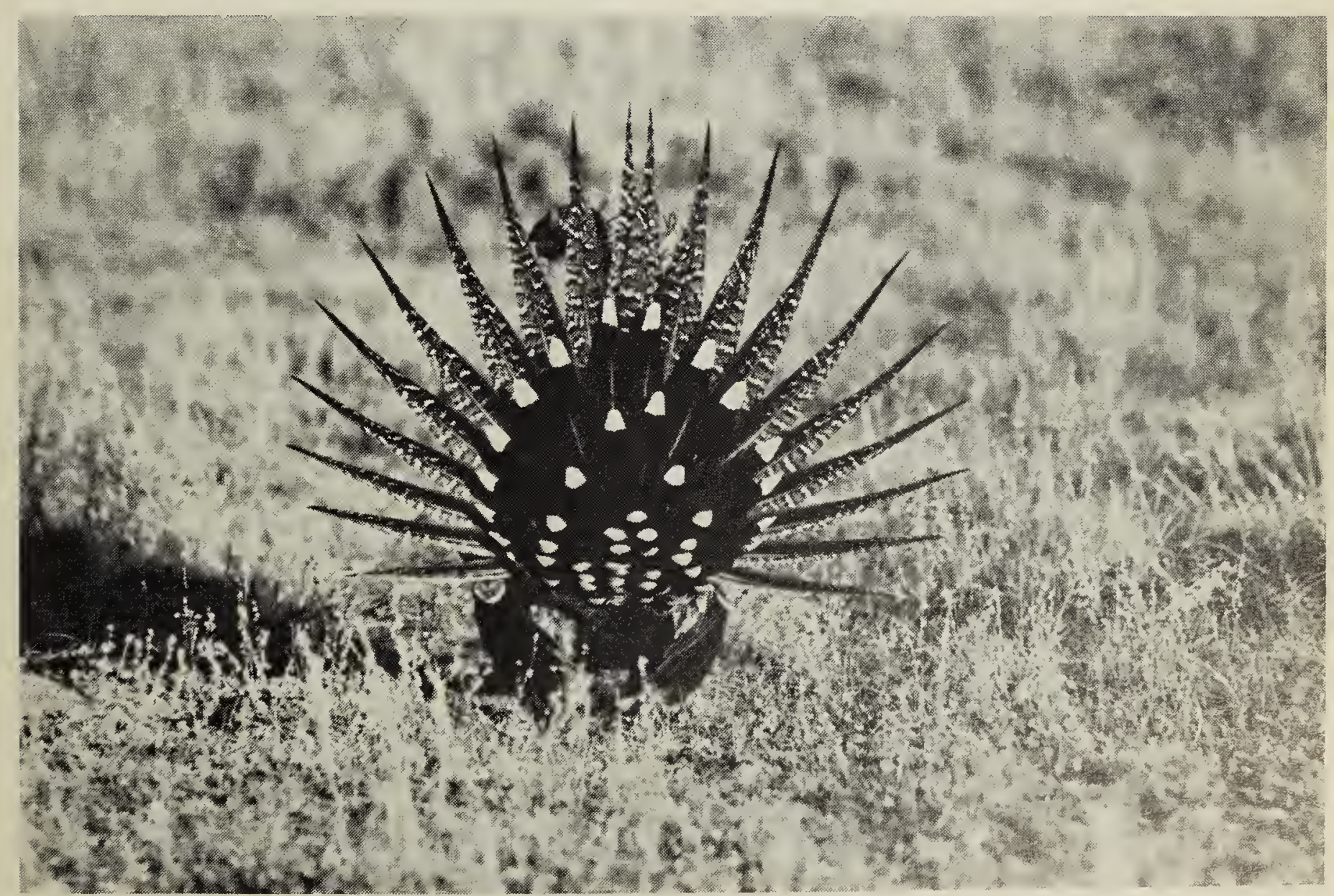

Sage Grouse. 